\title{
Management practices associated with conception rate and service rate of lactating Holstein cows in large, commercial dairy herds
}

\author{
J. M. Schefers, ${ }^{*} \dagger^{1}$ K. A. Weigel, ${ }^{*}$ C. L. Rawson, $\dagger$ N. R. Zwald, $\dagger$ and N. B. Cook \\ ${ }^{*}$ Department of Dairy Science, University of Wisconsin, Madison 53706 \\ †Alta Genetics, Watertown, WI 53094 \\ ¥School of Veterinary Medicine, University of Wisconsin, Madison 53706
}

\section{ABSTRACT}

Data from lactating Holstein cows in herds that participate in a commercial progeny testing program were analyzed to explain management factors associated with herd-average conception and service rates on large commercial dairies. On-farm herd management software was used as the source of data related to production, reproduction, culling, and milk quality for 108 herds. Also, a survey regarding management, facilities, nutrition, and labor was completed on 86 farms. A total of 41 explanatory variables related to management factors and conditions that could affect conception and service rate were considered in this study. Models explaining conception and service rates were developed using a machine learning algorithm for constructing model trees. The most important explanatory variables associated with conception rate were the percentage of repeated inseminations between 4 and 17 $\mathrm{d}$ post-artificial insemination, stocking density in the breeding pen, length of the voluntary waiting period, days at pregnancy examination, and somatic cell score. The most important explanatory variables associated with service rate were the number of lactating cows per breeding technician, use of a resynchronization program, utilization of soakers in the holding area during the summer, and bunk space per cow in the breeding pen. The aforementioned models explained 35\% and $40 \%$ of the observed variation in conception rate and service rate, respectively, and underline the association of herd-level management factors not strictly related to reproduction with herd reproductive performance.

Key words: reproductive performance, dairy cattle, management, machine learning

Received January 5, 2009.

Accepted November 24, 2009.

${ }^{1}$ Corresponding author: schefers@wisc.edu

\section{INTRODUCTION}

Reproductive performance is influenced by many environmental and management factors, such as accuracy of estrus detection, semen handling techniques, use of synchronization or resynchronization programs, transition cow management, metabolic health, udder health, cow comfort, and lameness (Lucy, 2001; Caraviello et al., 2006).

Fertility of the service sire (Kuhn and Hutchison, 2008) and correct thawing and handling of semen affect cow fertility. Improper semen handling techniques can lead to damaged sperm membranes, reduced motility, and sperm death due to heat- and cold-shock (Foote and Parks, 1993). Caraviello et al. (2006) noted that the temperature at which semen is thawed was a significant factor affecting the proportion of cows pregnant by $150 \mathrm{~d}$ in milk.

Tenhagen et al. (2004) compared the economic considerations between timed AI after synchronized ovulation to AI at estrus and noted that evaluation of synchronization protocols should include reproductive performance along with the appropriate costs of treatment. When estrus detection rates are poor in herds, Ovsynch (Pursley et al., 1995) may help reproduction by increasing the service rate.

Calving-related disorders such as metritis, retained placenta, ketosis, and displaced abomasum predispose cows to reduced reproductive efficiency (Stevenson and Call, 1988; Walsh et al., 2007). Furthermore, cows consuming less dry matter during the periparturient period have delayed first ovulation and reduced fertility (Staples et al., 1990) and are predisposed to diseases that affect fertility such as metritis (Huzzey et al., 2007). Pen moves, grouping strategies, and bunk space are just a few of the factors that affect the subsequent health and performance of the transition cow (Cook and Nordlund, 2004).

Chebel et al. (2004) noted that cows with mastitis were 2.8 times more likely to experience embryonic loss than cows that did not have mastitis. Furthermore, cows with subclinical or clinical mastitis before the 
first insemination tend to require a greater number of services per conception (Barker et al., 1998; Schrick et al., 2001; Santos et al., 2004).

Environmental conditions can have a major influence on a cow's ability or tendency to exhibit signs of estrus. Overcrowding and the presence of slippery floor surfaces can restrict mounting activity (Britt et al., 1986). Furthermore, mounting activity of cows with foot problems is reduced compared with cows with good foot health (Leonard et al., 1994). Garbarino et al. (2004) found that cows classified as lame had 3.5 times greater odds of delayed cyclicity compared with cows classified as nonlame.

Although many of the aforementioned studies have focused on a few related factors that may affect reproductive performance, they tend to be limited in scope. Recently, Caraviello et al. (2006) used a machine learning algorithm to construct alternating decision trees for prediction of first-service conception rate and pregnancy status at $150 \mathrm{~d}$ postpartum for individual animals. Such algorithms are powerful and flexible, because they can accommodate missing data, multicollinearity, and numerous explanatory variables. Caraviello et al. (2006) focused on classification of binary outcomes (i.e., pregnant or not pregnant) and the resulting decision trees were very complex. The objective of this study was to identify factors associated with conception rate and service rate from a large number of interrelated directly and indirectly associated variables using machine learning algorithms. The objective of the machine learning algorithms was to determine the predictability of such a method when a large number of variables associated with conception and service rate were missing. This was an important objective because the data set had many missing explanatory variables.

\section{MATERIALS AND METHODS}

Data regarding production, reproduction, culling, and milk quality of lactating Holstein cows in 108 dairy herds in the Alta Genetics (Watertown, WI) Advantage progeny testing program were extracted from Dairy Comp 305 herd management software (Valley Ag Software, Tulare, CA). The herds used in this study were located in Wisconsin (40), New York (20), Minnesota (12), California (11), Michigan (4), Pennsylvania (4), Iowa (3), Idaho (3), Indiana (2), Ohio (2), South Dakota (2), Illinois (1), Maryland (1), Oregon (1), Vermont (1), and Washington (1). Herd sized ranged from 163 to 3,394 milking cows, and mean herd size was 781 milking cows. Mean conception rates for individual herds ranged from 20 to $44 \%$, with an overall mean of $32.2 \%$. Mean service rates ranged from 39 to $76 \%$, with an overall mean of $56.9 \%$. Within each herd, annual conception rate and service rate were averaged across all successive 21-d time periods from September 1, 2006 to September 1, 2007. Conception rate was calculated as

$$
\text { Conception rate }=100 \times \frac{(\text { total no. of confirmed pregnancies })}{(\text { total no. of breedings })},
$$

Furthermore, service rate was calculated as

$$
\text { Service rate }=100 \times \frac{(\text { total no. of breedings })}{(\text { total no. of cows eligible for breeding })} .
$$

Cows that were eligible for breeding met the following criteria:

1. Past the voluntary waiting period (VWP) at the beginning of the period.

2. Nonpregnant at the beginning of the period.

3. Not marked as "do not breed" before or during the period.

4. Cow is present for $>50 \%$ of the period.

5. Known outcome if inseminated before or during the period.

The VWP for a herd was defined as the number of days postpartum when $5 \%$ of cows had received their first AI. It was necessary to calculate a herd-specific VWP from the raw data, because the Dairy Comp 305 software assumes a 50-d VWP. Somatic cell score was calculated as the annual herd average from September 1, 2006 to September 1, 2007.

In addition, a survey regarding transition cow management, facilities, reproductive programs, and labor on a subset of 86 farms was completed by Alta Advantage consultants between February 1 and April 1, 2007. A total of 41 potential explanatory variables related to management factors and conditions that may affect conception rate or service rate were assessed in the survey. Preference was given to explanatory variables related to management, facilities, nutrition, and labor that could be easily and consistently measured by the Alta Advantage consultants in a 1-h walkthrough of the dairy. Furthermore, the survey used for this study was completed on only 86 of the 108 herds considered for this study because of time and labor constraints for data collection. Means, standard errors, and frequencies for explanatory variables considered in this study are provided in Table 1, and case definitions for selected explanatory variables are provided in Table 2 . Because some of the continuous or categorical variables considered in this study did not apply to some herds, a 
dummy variable representing "does not apply" was used when applicable. Furthermore, values that were missing or incomplete were considered as missing values in the subsequent analyses.

A regression-based decision tree was used to explain management factors associated with conception rate and service rate. The M5P algorithm (Quinlan, 1992) for building regression-based trees, as implemented in the WEKA 3.4 Data Mining Software (Witten and Frank, 2005) was used. The M5P algorithm creates a model tree that represents a combination of a decision tree (i.e., a tree diagram that is used for predicting a specific outcome in which the branches represent variables associated with the outcome) and one or more linear regression models, for predicting a continuous outcome in 3 stages: construction, pruning, and smoothing.

As described by Quinlan (1992), construction of a model tree begins with the total set of observations designated by $T$. Each case is specified by the values of a fixed set of discrete and numeric attributes, as well as an associated outcome. The aim is to build a model tree that relates outcomes of the training cases to their corresponding attributes. Model trees are created by the divide-and-conquer method. The set $T$ of training cases may be associated with a leaf node, or $T$ may be split into subsets corresponding to the outcome of a test. This process continues and is applied to all subsets recursively.

Table 1. Census data collected from each of the 108 herds participating in the study, which represented potential explanatory variables for describing conception rate and service rate

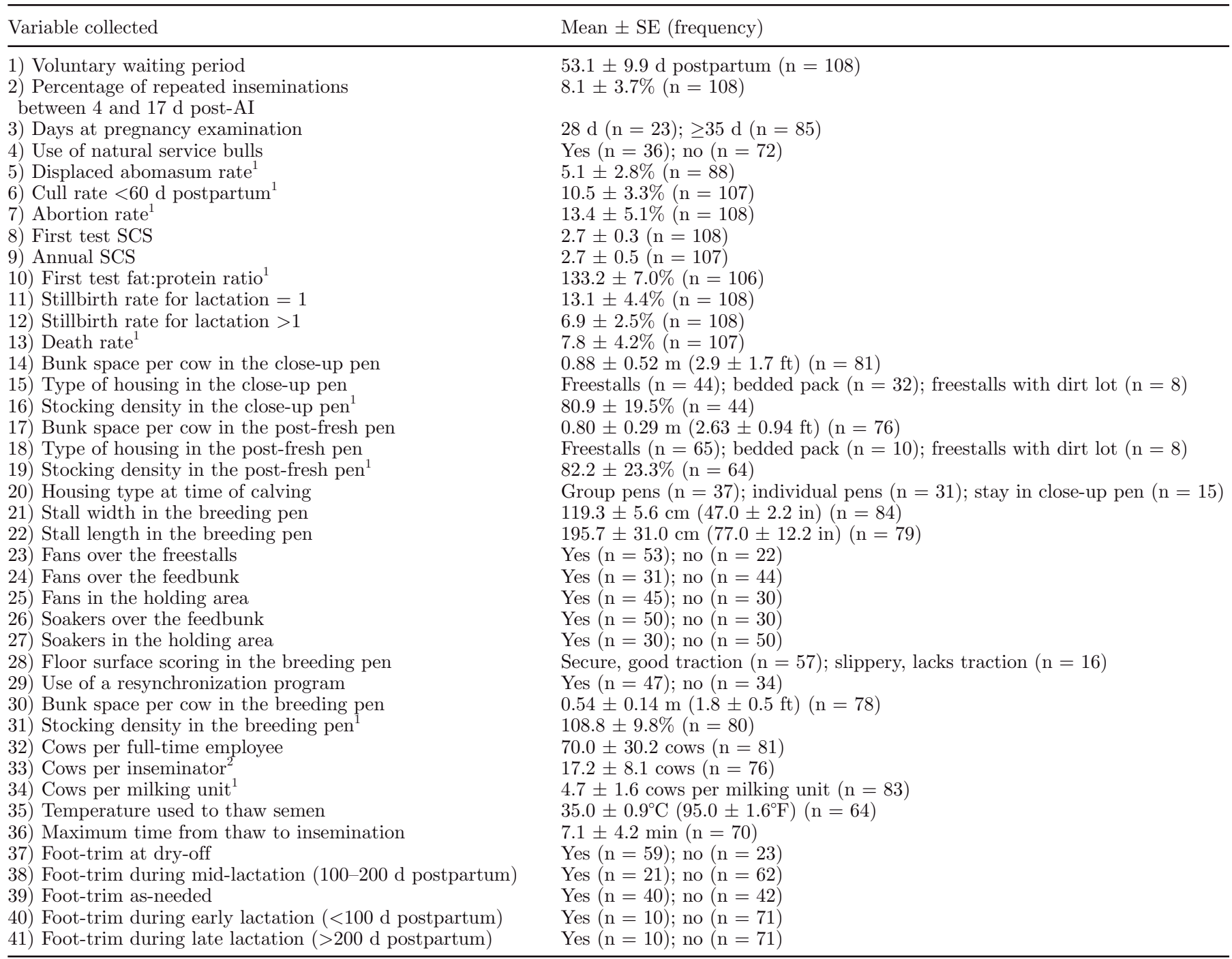

${ }^{1}$ Case definitions provided in Table 2 .

${ }^{2}$ After normalization with square root transformation. 
Table 2. Case definitions for potential explanatory variables for describing conception rate and service rate

\begin{tabular}{ll}
\hline Variable $^{1}$ & Case definition \\
\hline 5) Displaced abomasum rate & (Total no. displaced abomasums per year)/(total no. calvings per year) \\
6) Cull rate $<60 \mathrm{~d}$ postpartum & (Total no. sold cows + no. dead cows $<60 \mathrm{~d}$ postpartum \\
& per year)/(total no. calvings per year) \\
7) Abortion rate & $100 \times[($ first test fat percentage)/(first test protein percentage $)]$ \\
10) First test fat:protein ratio & $100 \times[($ total no. dead cows per year)/(total no. calvings per year) $]$ \\
13) Death rate & $100 \times[($ average no. cows in the close-up pen)/(no. stalls in the close-up pen $)]$ \\
16) Stocking density: close-up pen & $100 \times[($ average no. cows in the post-fresh pen)/(no. stalls in the post-fresh pen) $]$ \\
19) Stocking density: post-fresh pen & $100 \times[($ average no. cows in the breeding pen $) /($ no. stalls in the breeding pen $)]$ \\
31) Stocking density: breeding pen & (Maximum no. cows in the holding area at any time $) /($ no. milking units) \\
34) Cows per milking unit &
\end{tabular}

${ }^{1}$ Numbers refer to variables in Table 1.

The first step when building the tree is to calculate the standard deviation of the outcomes of cases in T. A splitting criterion is used to determine which attribute, if any, should be used to split the portion $T$ of the training data that reaches a particular node based on maximization of the expected error reduction. The expected error reduction, or standard deviation reduction (SDR), is calculated by

$$
S D R=S D(T)-\sum_{i} \frac{\left|T_{i}\right|}{|T|} \times S D\left(T_{i}\right),
$$

where $T$ is the set of training cases that reach the node, and $T_{1}, T_{2}, \ldots$ are the sets that result from splitting the node according to the chosen attribute. For missing values, the splitting criterion is modified, and SDR is calculated by

$$
S D R=\frac{m}{|T|} \times S D(T)-\sum_{i \in\{L, R\}}\left|\frac{T_{i}}{T}\right| \times S D\left(T_{i}\right),
$$

where $m$ is the number of instances without missing values for the attribute, $T$ is the set of instances that reach this node, and $T_{L}$ and $T_{R}$ are the sets that result from splitting on this attribute. When the splitting procedure ends, global replacement of all missing values is based on the mean/mode values of the corresponding attributes of the training examples reaching the leaves. During testing an unknown attribute value is replaced by the mean/mode value of that attribute for all training instances that reach the node, with the effect of choosing always the most populous subnode. The splitting process terminates when too few instances remain (e.g., $<4)$ or when the class values of the instances that reach a node vary slightly; that is, when their standard deviation is only a small fraction (e.g., $<5 \%$ ) of the standard deviation of the original training set.

The pruning procedure uses an estimate of the expected error of $T$ at each node. The absolute difference between the predicted value and actual value is averaged over each of the training instances that reach the node. Because this average underestimates the expected error for unseen cases, it is multiplied by the factor $(n+v) /$ $(n-v)$, where $n$ is the number of training instances that reach the node and $v$ is the number of parameters in the linear model at the node.

Finally, a smoothing process is used to compensate for discontinuities between adjacent linear models at adjacent leaves of the pruned tree. The smoothing calculation used for regression-based trees is

$$
p^{\prime}=\frac{n p+k q}{n+k},
$$

where $p^{\prime}$ is the prediction passed up to the next higher node, $p$ is the prediction passed to this node from below, $q$ is the value predicted by the model at this node, $n$ is the number of training instances that reach the node below, and $k$ is a smoothing constant (default $=15$ ).

Performance of the M5P algorithm was assessed using 10-fold cross-validation. Because there was a total of 108 observations used in the M5P analysis, each fold consisted of roughly 10 herds. For each of 10 folds (i.e., samples drawn without replacement) of the original data, a model was constructed using cases in the remaining 9 folds and tested on cases in the 10th fold. Finally, conception rate and service rate were analyzed with a traditional linear statistical model using the GLM procedure of SAS (version 9.1.3, SAS Institute, 2008). Backward deletion was used to determine the optimal combination of explanatory variables, where "optimal" was defined as the combination with the lowest Akaike's information criterion, and all terms in the equation were significant at the $P \leq 0.05$ level.

\section{RESULTS AND DISCUSSION}

\section{Conception Rate}

The final model for describing conception rate, which was based on the largest correlation coefficient and 

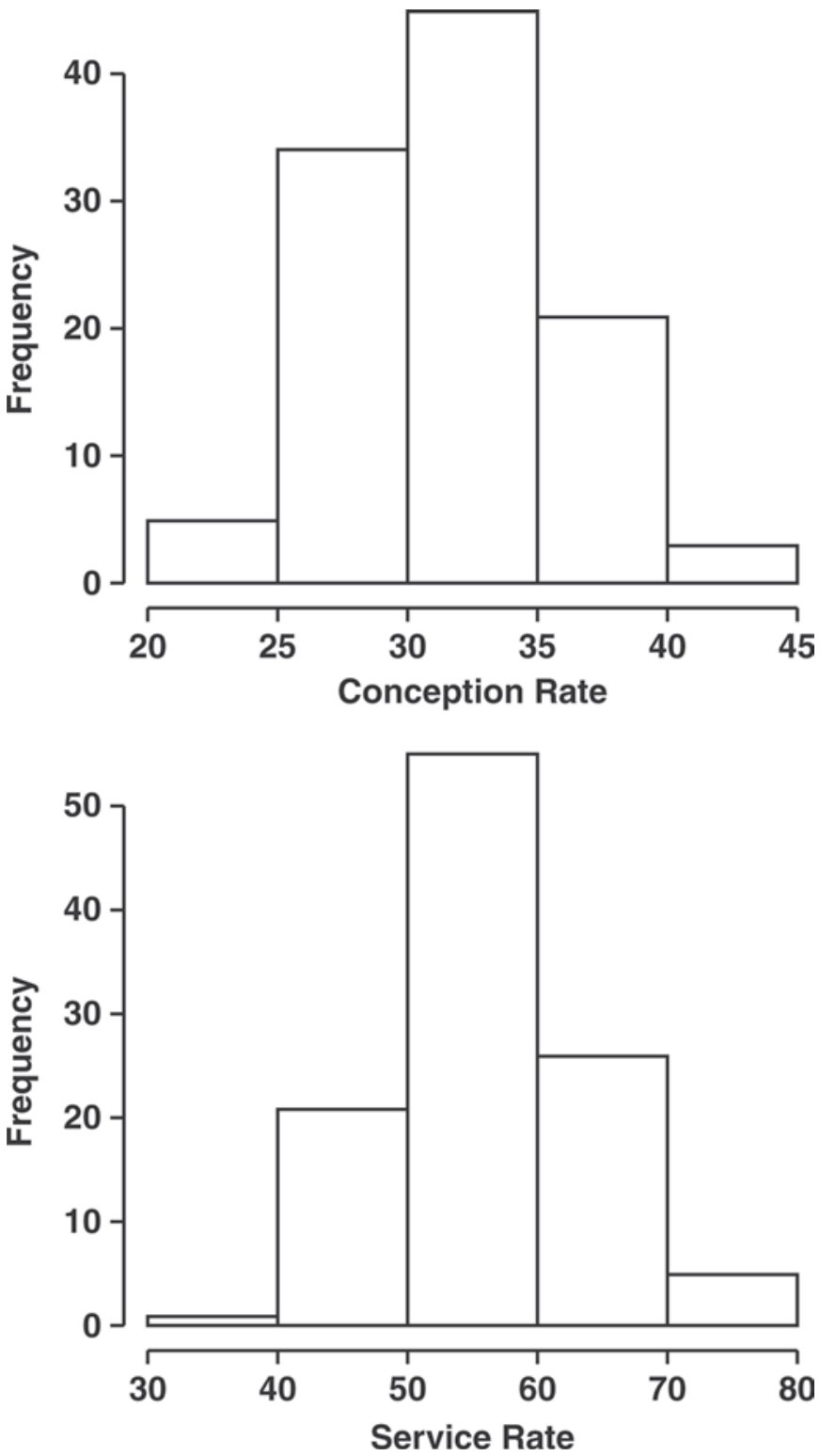

Figure 1. Histograms for conception rate $($ mean $=32.2, \mathrm{SD}=4.5)$ and service rate for 108 herds $($ mean $=56.9, \mathrm{SD}=7.6$ ). smallest root mean squared error from the M5P algorithm for the whole model, was as follows:

$$
\begin{aligned}
y_{i}=\mu+ & \mathrm{b}_{1} \mathrm{ACC}_{i}+\mathrm{b}_{2} \mathrm{STOCK}_{i}+\mathrm{b}_{3} \mathrm{VWP}_{i}+\mathrm{b}_{4} \mathrm{SCS}_{i} \\
& +\mathrm{b}_{5} \mathrm{PGEXAM}_{i}+\mathrm{b}_{6} \mathrm{ABORT}_{i}+\mathrm{e}_{i},
\end{aligned}
$$

where $y_{i}=$ mean conception rate within herd $i ; \mu=$ overall mean; $\mathrm{ACC}_{i}=$ accuracy, defined as the percentage of repeated inseminations between 4 and $17 \mathrm{~d}$ postAI for herd $i$, with regression coefficient $\mathrm{b}_{1}$; STOCK $_{i}$ $=$ stocking density in the breeding pen for herd $i$, with regression coefficient $\mathrm{b}_{2} ; \mathrm{VWP}_{i}=$ length of the VWP for herd $i$, with regression coefficient $\mathrm{b}_{3} ; \mathrm{SCS}_{i}=$ somatic cell score for herd $i$, with regression coefficient $\mathrm{b}_{4} ; \mathrm{PGEXAM}_{i}=$ days from insemination to pregnancy examination for herd $i$, with regression coefficient $\mathrm{b}_{5}$; $\mathrm{ABORT}_{i}=$ abortion rate for herd $i$, with regression coefficient $\mathrm{b}_{5}$, and $\mathrm{e}_{i}=$ random error.

During the pruning and smoothing process, the regression-based model tree was simplified into a single linear equation. For the model calculated by the M5P algorithm, the cross-validation coefficient of determination $\left(\mathrm{R}^{2}\right)$ was 0.25 . Regression coefficients are provided in Table 3. A histogram for conception rate for the 108 herds is provided in Figure 1.

Next, the GLM procedure (SAS Institute, 2008) and backward deletion were used to predict conception rate. Interactions were ignored because the number of observations was insufficient to evaluate a large number of 2or 3-way interactions. A total of 29 herds were removed from this analysis because of missing values for some of the predictor variables. Therefore, 79 herds were used to assess significance of the predictor variables using ANOVA type III sums of squares.

Four variables, the percentage of repeated inseminations between 4 and $17 \mathrm{~d}$ post-AI $(P<0.001)$, stocking density in the breeding pen $(P<0.05)$, length of the VWP $(P=0.05)$, and days from insemination to pregnancy examination $(P<0.05)$ were associated

Table 3. Regression coefficients from the M5P machine learning algorithm and ANOVA estimates based on herds with no missing data for the model describing conception rate (\%)

\begin{tabular}{lccc}
\hline & \multirow{2}{*}{$\begin{array}{c}\text { M5P } \\
\text { Variable }\end{array}$} & \multicolumn{2}{c}{ ANOVA $^{2}$} \\
\cline { 3 - 4 } coefficients $^{1}$ & Estimates $\pm \mathrm{SE}$ & $P$-value \\
\hline Intercept & 45.76 & $46.57 \pm 5.47$ & $<0.0001$ \\
Repeated inseminations & -0.37 & $-0.39 \pm 0.11$ & $<0.001$ \\
between 4 and 17 d (\%) & & & 0.02 \\
Stocking density in the breeding pen (\%) & -0.08 & $-0.10 \pm 0.04$ & 0.02 \\
Days at pregnancy examination = 28 d & -2.50 & $-2.15 \pm 0.93$ & 0.04 \\
Voluntary waiting period (d) & 0.09 & $0.09 \pm 0.04$ & Not in final model \\
SCS (log SCS) & -1.97 & $-1.43 \pm 0.81$ & \\
Abortion rate (\%) & -0.15 & Not in final model & \\
${ }^{1} \mathrm{R}^{2}=0.25$; root mean squared error $=3.88$. & & & \\
${ }^{2} \mathrm{R}^{2}=0.35$. & & &
\end{tabular}


with conception rate. Somatic cell score $(P=0.08)$ also tended to be associated with conception rate. Regression coefficients, standard errors, and $P$-values from the linear regression analysis are provided in Table 3. Overall, the $\mathrm{R}^{2}$ value of the linear regression model for conception rate in the 79 herds with no missing data was 0.35 .

Accuracy of estrus detection, which was measured as the percentage of repeated inseminations following a cycle of 4 to $17 \mathrm{~d}$ post-AI, was a significant predictor of conception rate in the present study. As the percentage of inseminations during this period increased, herd average conception rate decreased.

High stocking densities in the breeding pen were also associated with reduced conception rates. Overstocking of the breeding pens is often overlooked when considering factors associated with reproductive performance. Overstocking freestall barns reduces lying time (Friend et al., 1977; Wierenga and Hopster, 1990; Fregonesi et al., 2007) and increases the frequency of aggressive interaction because of competition for stalls and resources (Fregonesi and Leaver, 2002; Fregonesi et al., 2007). In most cases, when freestalls are overstocked, bunk space is restricted simultaneously. Caraviello et al. (2006) reported that bunk space per cow was one of the most important explanatory variables affecting pregnancy status at $150 \mathrm{~d}$ postpartum, although it was not found to be significant in the current model.

In the present study, a longer VWP was associated with improved conception rate. Caraviello et al. (2006) found a positive relationship between length of the VWP and first-service conception rate. Foote (1978) found that cows serviced before $50 \mathrm{~d}$ postpartum had a lower conception rate than those serviced after a longer postpartum period. Also, cows in an Ovsynch group with VWP $>76 \mathrm{~d}$ had a greater conception rate than cows with a VWP between 60 and $75 \mathrm{~d}$ (Pursley et al., 1997). In contrast, Schneider et al. (1981) observed that cows serviced very late after calving $(93 \pm 17 \mathrm{~d})$ had lower fertility than cows serviced earlier $(72 \pm 18$ d). The maximum VWP in the present study was $80 \mathrm{~d}$ postpartum, so the efficacy of a VWP greater than 80 $\mathrm{d}$ postpartum is subject to greater uncertainty because of extrapolation.

Herds with high SCS tended to have lower conception rates. In previous studies, cows that experienced subclinical or clinical mastitis before the first insemination required a greater number of services per conception (Barker et al., 1998; Schrick et al., 2001; Santos et al., 2004) and were 2.8 times more likely to lose their pregnancies than those not experiencing mastitis (Chebel et al., 2004). Although SCS is not equivalent to clinical mastitis, it can used as an indicator of mastitis because the genetic correlation between SCS and clinical mastitis is 0.72 (Rupp and Boichard, 1999).

Finally, it should be noted that herds that routinely carried out pregnancy examinations at $28 \mathrm{~d}$ after breeding had higher conception rates than herds that performed pregnancy examinations at $\geq 35 \mathrm{~d}$ after breeding $(P=0.02)$. Early in gestation, the frequency of embryonic death is high. For example, among cows diagnosed pregnant at $\leq 28$ d post-AI, 10 to $16 \%$ experience embryonic loss by 56 d post-AI (Mee et al., 1994; Vasconcelos et al., 1997; Fricke et al., 1998). In addition, with 28-d pregnancy examinations, there is the potential for incorrect diagnosis. Pieterse et al. (1990) found that sensitivity and specificity of pregnancy diagnosis with ultrasound when conducted between 21 and $25 \mathrm{~d}$ post-AI was lower than pregnancy diagnosis conducted between 26 and $33 \mathrm{~d}$ post-AI. Uncertain cases may be (conservatively) labeled as pregnant so that the cows in question are not subject to resynchronization. After reexamination, these cows may not be pregnant, and these cases show up as embryonic losses (even though the cow may not have been pregnant at the time of the initial examination). In the present study, herds that had 28-d pregnancy examinations had a $>2 \%$ higher average conception rate than those that carried out $\geq 35 \mathrm{~d}$ pregnancy examinations. A univariate analysis was conducted to determine if herds that used 28-d pregnancy examinations also had an apparent abortion risk. Abortion rate was the response variable, and days from insemination to pregnancy examination was the predictor variable. Herds that used 28-d pregnancy examinations had a $1.96 \%$ higher apparent abortion rate $(P=0.10)$. Because the effects of days at pregnancy examination and abortion rate canceled each other, we concluded that early pregnancy diagnosis was not a useful management practice for improving conception rate.

\section{Service Rate}

The final model for describing service rate, which was based on the largest correlation coefficient and lowest root mean squared error from the M5P machine learning algorithm, was as follows:

$$
\begin{aligned}
y_{i j k}= & \mu+\mathrm{RESY}_{i}+\mathrm{SOAK}_{j}+\mathrm{b}_{1} \mathrm{BUNK}_{i j k} \\
& +\mathrm{b}_{2} \mathrm{CPB}_{i j k}+\mathrm{b}_{3} \mathrm{ACC}_{i j k}+\mathrm{e}_{i j k},
\end{aligned}
$$

where $y_{i j k}=$ mean service rate within herd $k ; \mu=$ overall mean; $\operatorname{RESY}_{i}=$ fixed effect of resynchronization program (yes, no); $\mathrm{SOAK}_{j}=$ fixed effect of utilization of soakers in the holding area during summer months 
Table 4. Regression coefficients from the M5P machine learning algorithm and ANOVA estimates based on herds with no missing data for the model describing service rate (\%)

\begin{tabular}{lccc}
\hline & & \multicolumn{2}{c}{ ANOVA $^{2}$} \\
\cline { 3 - 4 } Variable & $\begin{array}{c}\text { M5P regression } \\
\text { coefficient }^{1}\end{array}$ & Estimate \pm SE & $P$-value \\
\hline Intercept & 37.7 & $40.7 \pm 2.9$ & $<0.0001$ \\
Repeated insemination between 4 and $17 \mathrm{~d}(\%)$ & 1.0 & $0.84 \pm 0.19$ & $<0.001$ \\
Cows per inseminator ${ }^{3}(\mathrm{n})$ & 0.14 & $0.003 \pm 0.002$ & 0.04 \\
Use a resynchronization program = Yes & 2.9 & $4.0 \pm 1.5$ & 0.009 \\
Use soakers in the holding area = Yes & 4.2 & $3.6 \pm 1.5$ & 0.02 \\
Bunk space per cow in the breeding pen $(\mathrm{cm})$ & 3.2 & $2.5 \pm 1.5$ & 0.10 \\
${ }^{1}$ Correlation coefficient $=0.59$; root mean squared error $=6.15$. & & \\
${ }^{2} \mathrm{R}^{2}=0.50$. & & & \\
${ }^{3}$ After square root transformation. & & &
\end{tabular}

(yes, no); BUNK $_{i j k}=$ bunk space per cow in the breeding pen for herd $k$, with regression coefficient $\mathrm{b}_{1}$; $\mathrm{CPI}_{i j k}$ $=$ square root of the total number of cows per inseminator for herd $k$, with regression coefficient $\mathrm{b}_{2}$; AC$\mathrm{C}_{i j k}=$ accuracy, defined as the percentage of repeated inseminations between 4 and $17 \mathrm{~d}$ post-AI for herd $k$, with regression coefficient $\mathrm{b}_{3}$; and $\mathrm{e}_{i j k}=$ random error.

Once again, during the pruning and smoothing process, the model tree was simplified into a single linear regression equation. For the model created by the M5P algorithm, $\mathrm{R}^{2}$ was 0.35 . Regression coefficients are provided in Table 4. A histogram for service rate for the 108 herds is provided in Figure 1.

Next, the GLM procedure in SAS (SAS Institute, 2008) with backward deletion was used to predict service rate. As noted earlier, the number of observations was insufficient to test all possible interactions between predictor variables. A total of 46 herds were removed from this analysis because of missing values for some of the predictor variables. Significance of the predictor variables was evaluated using the ANOVA type III sum of squares. The $\mathrm{R}^{2}$ of the linear model for service rate based on 62 herds with no missing data was 0.50 . Regression coefficients, standard errors, and $P$-values from the linear model analysis are provided in Table 4 . Three variables, percentage of repeated inseminations between 4 and $17 \mathrm{~d}(P<0.001)$, utilization of a resynchronization program $(P<0.01)$, and the utilization of soakers in the holding area $(P=0.02)$ were associated with service rate.

Resynchronization programs had a beneficial effect on service rate. Least squares means service rate was $58.6 \pm 1.0$ for herds with a resynchronization program and $53.8 \pm 1.3$ for herds without a resynchronization program. Herds that used a resynchronization program in this study gave $\mathrm{GnRH}$ either $7 \mathrm{~d}$ before a pregnancy exam or on the day of pregnancy exam. A univariate analysis was used to determine if a difference existed in service rate between the 2 resynchronization methods.
There was no significant difference in the 2 resynchronization method for the herds in this study $(P=0.47)$; however, herds that did not have a resynchronization program had lower service rates than herds that did have a resynchronization program $(P<0.01)$. Herds that rapidly achieve AI services after nonpregnant diagnoses are able to decrease the interval between AI services, thereby increasing the AI service rate (Fricke, 2002). Resynchronization programs generally utilize Ovsynch, a synchronization regimen using sequential injections of $\mathrm{GnRH}$ and $\mathrm{PGF}_{2 \alpha}$ to control ovulation for timed insemination (Pursley et al., 1995). Sterry et al. (2006) compared 2 different resynchronization strategies. One group of cows received $\mathrm{GnRH}$ at $26 \mathrm{~d}$ after timed AI (TAI) and continued the resynchronization program only if the cows were diagnosed not pregnant by ultrasonography at $33 \mathrm{~d}$ after TAI, whereas another group of cows began the resynchronization program only after being diagnosed not pregnant $33 \mathrm{~d}$ after TAI. Despite the increased service rate, delaying initiation of the resynchronization program until $33 \mathrm{~d}$ after TAI increased the pregnancy rate per AI in that study. Fricke et al. (2003) also found that initiation of resynchronization $19 \mathrm{~d}$ after first TAI service resulted in lower pregnancy rate per AI compared with initiation of resynchronization 26 or $33 \mathrm{~d}$ after the first TAI.

As breeding technicians in the present study gained responsibility for servicing a greater number of cows, we noted an increase in service rate. In large commercial dairy herds, a dedicated breeding technician is often responsible for the majority, if not all, of the inseminations. Because dedicated breeding technicians are able to focus on one area of management (i.e., reproductive management), they tend to service more cows compared with herds in which "everyone" is responsible for estrus detection.

Utilization of soakers in the holding area during the summer $(P=0.02)$ was associated with service rate. It is important to note that 24 of the 30 herds that 
used soakers in the holding area during the summer also used fan-based cooling systems in the holding area, and this finding highlights the general importance of heat stress abatement in large herds.

Increased bunk space per cow in the breeding pen $(P$ $=0.10)$ tended to be associated with improved service rate. Reduced access to feed may influence metabolic status, especially in early lactation (Cook and Nordlund, 2004), which may influence the onset of estrus activity. However, this finding is associative, not causal. For example, reduced bunk space also limits the number of available lock ups, which may affect compliance for the administration of estrus synchronization programs, and in most cases when bunk space is restricted, cows are also overstocked relative to stalls, resulting in reduced lying time and increased aggressive interactions due to competition for a place to rest (Fregonesi and Leaver, 2002; Fregonesi et al., 2007). Caraviello et al. (2006) reported that bunk space per cow was one of the most important explanatory variables affecting pregnancy status at $150 \mathrm{~d}$ postpartum.

Finally, the percentage of repeated inseminations between 4 and $17 \mathrm{~d}$ post-AI (i.e., accuracy of estrus detection) had a significant $(P<0.001)$ effect on service rate. As the percentage of repeated inseminations between 4 and $17 \mathrm{~d}$ post-AI increased by $1.0 \%$, service rate increased by 1.0 and $0.84 \%$ for the M5P and ANOVA models, respectively. Despite the association between accuracy of estrus detection and service rate, this measure of reproductive efficiency is not a suitable method for improving service rate. First, for reproductive troubleshooting, it is impractical to recommend inseminating cows when they are not in estrus to increase service rate. Second, herds with poor accuracy of estrus detection had lower conception rates $(P$ $<0.001)$. Furthermore, a high percentage of repeated inseminations during the period from 4 to $17 \mathrm{~d}$ post-AI is often the result of observing cows in visual heat (e.g., standing heat, mucus, increased activity) after a failed insemination from a synchronization program (e.g., Ovsynch, Co-Synch). Cows observed in estrus 4 to 17 d post-AI should be reinseminated. However, if a high percentage of cows are reinseminated 4 to $17 \mathrm{~d}$ post-AI in a herd, problems may exist in estrus detection or synchronization of ovulation. Reimers et al. (1985) suggested that many cows not in estrus on the day of their first postpartum service are actually near the middle of a normal estrous cycle. This indicates a failure in observing estrus.

\section{CONCLUSIONS}

Overall, the M5P machine learning algorithm used in the present study identified key explanatory variables for improving herd average conception rate and service rate, and underlined the association of herd-level management factors not strictly related to reproduction with herd reproductive performance. Because of the structure of the data in this study, the M5P algorithm was not able to build and prune a decision tree; instead, the final models for conception and service rate were linear models. The ability of the M5P algorithm to accommodate missing values for potential explanatory variables did not make it any more useful than traditional linear model methods. Important environmental and management factors identified that were associated with herd conception rate and service rate performance included VWP interval, estrus detection accuracy, number of cows per inseminator, use of a resynchronization program, udder health, heat abatement, days from insemination to pregnancy examination, and stocking density in the breeding pen.

\section{ACKNOWLEDGMENTS}

The authors thank Alta Genetics (Watertown, WI) for providing the data, financial support, and staff time for this project. Cooperation from herds participating in the Alta Advantage progeny testing program is greatly appreciated, as is the work of Alta Advantage progeny testing consultants in collecting the on-farm data and Dairy Comp 305 files for these herds in the present study. Partial financial support of K. Weigel by the National Association of Animal Breeders (Columbia, $\mathrm{MO})$ is acknowledged.

\section{REFERENCES}

Barker, A. R., F. N. Schrick, M. J. Lewis, H. H. Dowlen, and S. P. Oliver. 1998. Influence of clinical mastitis during early lactation on reproductive performance of Jersey cows. J. Dairy Sci. 81:12851290.

Britt, J. H., R. G. Scott, J. D. Armstrong, and M. D. Whitacre. 1986. Determinants of estrous behavior in lactating Holstein cows. J. Dairy Sci. 69:2195-2202.

Caraviello, D. Z., K. A. Weigel, M. Craven, D. Gianola, N. B. Cook, K. V. Nordlund, P. M. Fricke, and M. C. Wiltbank. 2006. Analysis of reproductive performance of lactating cows on large dairy farms using machine learning algorithms. J. Dairy Sci. 89:4703-4722.

Chebel, R. C., J. E. P. Santos, J. P. Reynolds, R. L. A. Cerri, S. O. Juchem, and M. Overton. 2004. Factors affecting conception rate after artificial insemination and pregnancy loss in lactating dairy cows. Anim. Reprod. Sci. 84:239-255.

Cook, N. B., and K. V. Nordlund. 2004. Behavioral needs of the transition cow and considerations for special needs facility design. Vet. Clin. Food Anim. 20:495-520.

Foote, R. H. 1978. Reproductive performance and problems in New York dairy herds. Search Agric. Cornell Univ. Agric. Exp. Stn. $8: 1$.

Foote, R. H., and J. E. Parks. 1993. Factors affecting preservation and fertility of bull sperm: A brief review. Reprod. Fertil. Dev. 5:665-673.

Fregonesi, J. A., and J. D. Leaver. 2002. Influence of space allowance and milk yield level on behaviour, performance and health of dairy 
cows housed in strawyard and cubicle systems. Livest. Prod. Sci. $78: 245-257$.

Fregonesi, J. A., C. B. Tucker, and D. M. Weary. 2007. Overstocking reduces lying time in dairy cows. J. Dairy Sci. 90:3349-3354.

Fricke, P. M. 2002. Scanning the future-Ultrasonography as a reproductive management tool for dairy cattle. J. Dairy Sci. 85:1918-1926.

Fricke, P. M., D. Z. Caraviello, K. A. Weigel, and M. L. Welle. 2003. Fertility of dairy cows after resynchronization of ovulation at three intervals following first timed insemination. J. Dairy Sci. 86:3941-3950.

Fricke, P. M., J. N. Guenther, and M. C. Wiltbank. 1998. Efficacy of decreasing the dose of GnRH used in a protocol for synchronization of ovulation and timed AI in lactating dairy cows. Theriogenology 50:1275-1284.

Friend, T. H., C. E. Polan, and M. L. McGilliard. 1977. Free stall and feed bunk requirements relative to behavior, production and individual feed intake in dairy cows. J. Dairy Sci. 60:108-116.

Garbarino, E. J., J. A. Hernandez, J. K. Shearer, C. A. Risco, and W. W. Thatcher. 2004. Effect of lameness on ovarian activity in postpartum Holstein cows. J. Dairy Sci. 87:4123-4131.

Huzzey, J. M., D. M. Veira, D. M. Weary, and M. A. G. von Keyserlingk. 2007. Prepartum behavior and dry matter intake identify dairy cows at risk for metritis. J. Dairy Sci. 90:3220-3233.

Kuhn, M. T., and J. L. Hutchison. 2008. Prediction of dairy bull fertility from field data: Use of multiple services and identification and utilization of factors affecting bull fertility. J. Dairy Sci. 91:2481-2492.

Leonard, F. C., J. O'Connell, and K. O'Farrell. 1994. Effect of different housing conditions on behaviour and foot lesions in Friesian heifers. Vet. Rec. 134:490-494.

Lucy, M. C. 2001. Reproductive loss in high-producing dairy cattle: Where will it end? J. Dairy Sci. 84:1277-1293.

Mee, J. F., D. P. Ryan, and T. Condon. 1994. Ultrasound diagnosis of pregnancy in cattle. Vet. Rec. 134:532.

Pieterse, M. C., O. Szenci, A. H. Willemse, C. S. A. Bajcsy, S. J. Dieleman, and M. A. M. Taverne. 1990. Early pregnancy diagnosis in cattle by means of linear-array real-time ultrasound scanning of the uterus and a qualitative and quantitative milk progesterone test. Theriogenology 33:697-707.

Pursley, J. R., M. O. Mee, and M. C. Wiltbank. 1995. Synchronization of ovulation in dairy cows using $\mathrm{PGF}_{2 \alpha}$ and GnRH. Theriogenology 44:915-923.

Pursley, J. R., M. C. Wiltbank, J. S. Stevinson, J. S. Ottobre, H. A. Garverick, and L. L. Anderson. 1997. Pregnancy rates per artificial insemination for cows and heifers inseminated at a synchronized ovulation or synchronized estrus. J. Dairy Sci. 80:295-300.

Quinlan, J. R. 1992. Learning with continuous classes. Pages 343-348 in Proc. 5th Australian Joint Conference of Artificial Intelligence. World Scientific, Singapore.
Reimers, T. J., R. D. Smith, and S. K. Newman. 1985. Management factors affecting reproductive performance of dairy cows in the northeastern United States. J. Dairy Sci. 68:963-972.

Rupp, R., and D. Boichard. 1999. Genetic parameters for clinical mastitis, somatic cell score, production, udder type traits, and milking ease in first lactation Holsteins. J. Dairy Sci. 82:21982204.

Santos, J. E., R. L. Cerri, M. A. Ballou, G. E. Higginbotham, and J. H. Kirk. 2004. Effect of timing of first clinical mastitis occurrence on lactational and reproductive performance of Holstein dairy cows. Anim. Reprod. Sci. 80:31-45.

SAS Institute. 2008. SAS version 9.1.3. http://support.sas.com/ onlinedoc/913/docMainpage.jsp Accessed Jul. 1, 2008.

Schneider, F., J. A. Shelford, R. G. Peterson, and L. J. Fisher. 1981. Effects of early and late breeding of dairy cows on reproduction in current and subsequent lactations. J. Dairy Sci. 64:1996-2002.

Schrick, F. N., M. E. Hockett, A. M. Saxton, M. J. Lewis, H. H Dowlen, and S. P. Oliver. 2001. Influence of subclinical mastitis during early lactation on reproductive parameters. J. Dairy Sci. 84:1407-1412.

Staples, C. R., W. W. Thatcher, and J. H. Clark. 1990. Relationship between ovarian activity and energy status during the early postpartum period of high producing dairy cows. J. Dairy Sci. 73:938-947.

Sterry, R. A., M. L. Welle, and P. M. Fricke. 2006. Effect of interval from timed artificial insemination to initiation of resynchronization of ovulation on fertility of lactating dairy cows. J. Dairy Sci. 89:2099-2109.

Stevenson, J. S., and E. P. Call. 1988. Reproductive disorders in the periparturient dairy cow. J. Dairy Sci. 71:2572-2583.

Tenhagen, B. A., M. Drillich, R. Surholt, and W. Heuwieser. 2004 Comparison of timed AI after resynchronized ovulation to AI at estrus: Reproductive and economic considerations. J. Dairy Sci $87: 85-94$.

Vasconcelos, J. L. M., R. W. Silcox, J. A. Lacerda, J. R. Pursley, and M. C. Wiltbank. 1997. Pregnancy rate, pregnancy loss, and response to heat stress after AI at two different times from ovulation in dairy cows. Biol. Reprod. 56(Suppl. 1):140. (Abstr.)

Walsh, R. B., J. S. Walton, D. F. Kelton, S. J. LeBlanc, K. E. Leslie, and T. F. Duffield. 2007. The effect of subclinical ketosis in early lactation on reproductive performance of postpartum dairy cows. J. Dairy Sci. 90:2788-2796.

Wierenga, H. K., and H. Hopster. 1990. The significance of cubicles for the behaviour of dairy cows. Appl. Behav. Sci. 26:309-337.

Witten, I. H., and E. Frank. 2005. Data Mining: Practical Machine Learning Tools and Techniques. 2nd ed. Morgan Kaufmann, San Francisco, CA. 